\title{
Waste not, want not: Bentall style
}

\author{
Grayson H. Wheatley III, MD
}

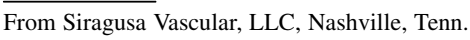

Disclosures: Dr Wheatley serves as a consultant for Medtronic, Terumo Aortic, Endologix, and Ethicon.

Received for publication June 19, 2018; revisions received June 19, 2018; accepted for publication June 21, 2018; available ahead of print Aug 4, 2018.

Address for reprints: Grayson H. Wheatley III, MD, Siragusa Vascular, LLC, 28 White Bridge Pike, Suite 200,

Nashville, TN 37205 (E-mail: ghw3rd@gmail.com).

J Thorac Cardiovasc Surg 2018;156:2087

$0022-5223 / \$ 36.00$

Copyright (C) 2018 by The American Association for Thoracic Surgery

https://doi.org/10.1016/j.jtcvs.2018.06.054

The aphorism "waste not, want not," as defined by the English Oxford Living Dictionary Web site, ${ }^{1}$ is loosely interpreted as, "If you use a commodity or resource carefully and without extravagance you will never be in need." In this issue of the Journal, Bellanti and colleagues $^{2}$ share their technique of preserving anatomic flow to the right coronary artery (RCA) in a type A aortic dissection in which the dissection affects the origin of an aberrant RCA.

Management of the coronary arteries during aortic root reconstruction for aortic dissection can present a challenging technical dilemma, particularly when the aortic dissection directly affects the ostium of the coronary arteries. At present, there are 3 fundamental surgical techniques available for restoring flow to the coronary arteries during a type A aortic dissection repair. First, if the coronary artery orifice and the surrounding rim of aortic tissue are unaffected by the aortic dissection, then the coronary arteries can be reimplanted directly into the neoroot, such as in a Bentall procedure. ${ }^{3}$ When considering whether to reimplant the coronary arteries, it is important to consider both the quality of the coronary button tissue and whether there is excessive tension on the coronary artery button anastomosis. Second, if the coronary button tissue is compromised by the aortic dissection, or if it appears that there would be unusual tension on the coronary artery anastomosis to the neoroot, then a Cabrol procedure can be performed. ${ }^{4}$ Third, the coronary artery can be ligated and surgically bypassed with conduit (usually a greater saphenous vein graft) instead of being implanted into the neoaortic root. ${ }^{5}$

The report of Bellanti and colleagues ${ }^{2}$ presents us with a fourth technical alternative to use when the origins of the coronary arteries are affected by a type A aortic dissection. A ring of pericardial tissue is sewn into the neoroot, to which the dissected RCA is anastomosed. The technical situation was even more challenging in the reported case because the origin of the RCA was anomalous and originated above the native sinotubular junction. Bellanti and colleagues $^{2}$ chose to resect the origin of the dissected portion of the RCA and implant the RCA directly into the

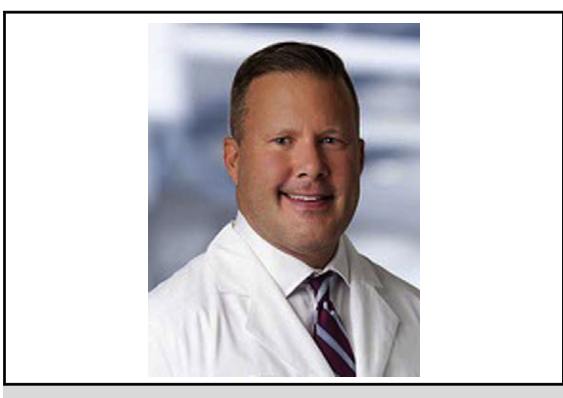

Grayson $\mathrm{H}$. Wheatley III, MD

Central Message

This study provides insight into an alternative technical solution for managing the coronary arteries in type A aortic dissection repair.

See Article page 2084.

pericardial patch in the neoroot at its normal anatomic location.

The advantage of this approach is that anatomic flow is maintained to the RCA. Patency of this type of reconstruction is generally more favorable than for a vein graft bypass to the affected coronary artery. The trade-off for maintaining antegrade flow is an extra suture line in the ne-aortic root, which carries the potential for increased suture line bleeding. The other advantage of reimplanting the RCA into the pericardial patch in the neoroot is that the workflow of the root replacement procedure is maintained without having to harvest greater saphenous vein. Having a new technical option in aortic surgeons' armamentarium for complex aortic root reconstructions in type A aortic dissections will assist surgeons in continuing to improve patient outcomes in type A aortic dissections and afford us the opportunity to "never be in need" when faced with a variety of aortic root replacement options.

\section{References}

1. Oxford University Press. English Oxford living dictionaries: waste not, want not Available at: https://en.oxforddictionaries.com/definition/us/waste_not,_want_ not. Accessed June 19, 2018.

2. Bellanti E, Bagozzi L, Gerosa G, Bottio T. Treatment of aortic dissection involving the right coronary. J Thorac Cardiovasc Surg. 2018;156:2084-6.

3. Di Marco L, Pacini D, Pantaleo A, Leone A, Barberio G, Marinelli G, et al. Composite valve graft implantation for the treatment of aortic valve and root disease: results in 1045 patients. J Thorac Cardiovasc Surg. 2016;152:1041-8.

4. Ziganshin BA, Williams FE, Tranquilli M, Elefteriades JA. Midterm experience with modified Cabrol procedure: safe and durable for complex aortic root replacement. J Thorac Cardiovasc Surg. 2014;147:1233-9.

5. Shahriari A, Eng M, Tranquilli M, Elefteriades JA. Rescue coronary artery bypass grafting (CABG) after aortic composite graft replacement. J Card Surg. 2009;24: $392-6$. 